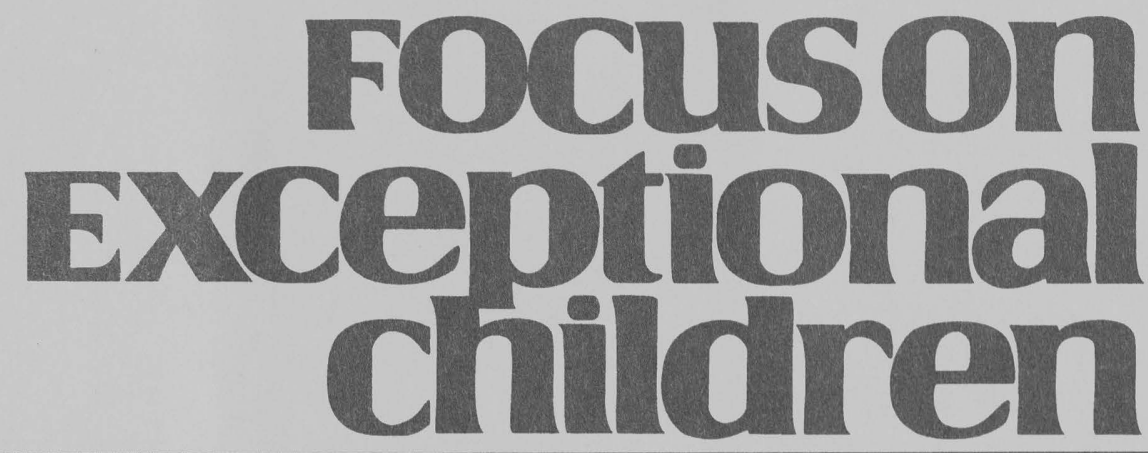

\title{
Down Syndrome: Literacy and Socialization in School
}

\author{
John Rynders
}

Parents of a child who has Down syndrome often feel that the school years are- to paraphrase Charles Dickens' famous words - "the best of times, the worst of times." They are the best of times because mothers and fathers can count on having 12-15 years of legally mandated, familiar, continuous, programming for their son or daughter. These same years, however, also can be the worst of times. The secondary schooling years in particular are those during which intellectually demanding tasks and peer pressure magnify the presence of the child's special needs (and perhaps vulnerability).

Excerpts from some of the EDGE parent interviews reveal a few of the challenges of the schooling years, not only for their child but for them as mothers and fathers as well. These interview findings were gathered when sons and daughters of EDGE parents were about 21 years of age.*

Father: I went with Jim to an open house at his junior high. He had a shop class, and I can't even remember what he did in it. I went with Jim to talk to the shop teacher. The teacher said, "It's a good thing there's a volunteer aide who comes in this class. Otherwise Jim wouldn't have done anything."

Mother: I sometimes thought they spent too much time on the vocational skills for Lee and gave up too easily on some of the other skills in his junior and senior year. He had good banking skills. He had good skills with a checkbook and with balancing his checkbook - that kind of thing. Even though he can't read, except for real simple things, I think they could have continued word recognition and sentence recognition training. I think they gave up on academics.

Mother: Teachers seemed to back off academic stuff. Tony was interested in reading and doing math. He actually could do it, and he took pride in that. Tony has a subscription to the newspaper. He looks at the headlines every morning. He looks at the sports page. He'll read the television page. He reads parts of stories that have to do with sports. He knows all the box scores.

Mother: They stopped any kind of reading in the program. I thought they should have continued that, because even though Bill wasn't the best in the world, you can't get any better if you don't have instruction and practice. That bothered me. Also,

John Rynders is a retired professor from the University of Minnesota. This article was adapted from a chapter in his book, coedited with J. Margaret Horrobin, entitled Down Syndrome: Birth to Adulthood: Giving Families an EDGE, published by Love Publishing Company.

*Names of the children in these quotes have been changed. 
they stopped completely with adding and subtracting. They used the calculator and went to the store and just worked on the money skills.

Father: Academically, they gave up on Sam. They really did. I can remember saying to one teacher, "Well, what about his reading skills?" She said, "If he hasn't done it by the time he's 16 , he's not going to do it." Well, I've got news for them. As soon as he gets out of high school, I'm going to get hold of the Literacy Council, and I'm going to see if I can get someone to work with him.

Mother: When I'd say I want Joe to keep up with his reading and that I'd like him to count the money, they'd say, "Well, have you ever considered that we need to get him out into the community?" Their big thing was to take him to the woods! They took him to the zoo. They took him to the apple orchard. It was the same thing every year. He didn't even want to go to these places.

Father: To this day he doesn't want to go to the zoohe's been there so many times.

Mother: Yes, to the Shrine Circus, too. You know what he says to this day: "If I was still in high school, I'd have to go to that darn Shrine Circus." (Laughter)

\section{Focuson
Exceptional children}

ISSN $0015-511 \mathrm{X}$

FOCUS ON EXCEPTIONAL CHILDREN (USPS 203-360) is published monthly except June, July, and August as a service to teachers, special educators, curriculum specialists, administrators, and those concerned with the special education of exceptional children. This publication is annotated and indexed by the ERIC Clearinghouse on Handicapped and Gifted Children for publication in the monthly Current Index to Journals in Education (CIJE) and the quarterly index, Exceptional Children Education Resources (ECER). The full text of Focus on Exceptional Children is also available in the electronic versions of the Education Index. It is also available in microfilm from Xerox University Microfilms, Ann Arbor, MI. Subscription rates: individual, \$36 per year; institutions, \$48 per year. Copyright (c) 2005, Love Publishing Company. All rights reserved. Reproduction in whole or part without written permission is prohibited. Printed in the United States of America. Periodical postage is paid at Denver, Colorado. POSTMASTER: Send address changes to:

Love Publishing Company

Executive and Editorial Office P.O. Box 22353

Denver, Colorado 80222

Telephone (303) 221-7333

Susan T. Warhover Editor
Stanley F. Love Publisher
Father: Sally was taken advantage of. And not just the sexual experiences. Some of the boys-classmateswould take advantage of her. They would get her to buy things for them or give them money.

Mother: I have mixed feelings about placing students who are mentally handicapped in high schools with typical peers. The students in special education have opportunities to meet students in regular ed classes, but they seldom are truly included. In a segregated setting students develop the same social strata as typical peers, have many of the same extracurricular and social events, and are included. My son and his friends did attend some of the extracurricular events such as basketball games, the Homecoming game and dance, Prom and the all-night graduation party at the regular high school they attended. They remained in their own group and were not a true part of the larger student body at these events.

Regular ed students may offer a high-five in the hall or say "Hi," but they don't call on the phone, invite special ed students to parties, or call for a date. This isn't a criticism. It's a statement of reality. Did John benefit from attending a regular high school versus a segregated site? It's hard to judge. Is he better prepared for living and working in the real world? He works downtown, rides the city bus to and from work. Did he develop these skills because of his high school experience? We'll never know for sure.

Mother: Just putting kids in a room with their chronological peers doesn't mean they're mainstreamed. I've watched carefully when Susan was going through [regular] high school. If she ever had made friends, or even an acquaintance, just a normal child to say, "Hi, Susan," it would have been great. I think it was good that she was able to go to that school, that she was with the other kids, but I really don't think Susan got very much out of her classes. Nondisabled kids want to keep up with their peers, and they don't want to be seen with those "strange" people. These are strong words, but still, I haven't seen any effort by the normal kids to be friendly.

We can readily detect two recurring quandaries in EDGE parents' comments: Should I argue for a strong and continuing academic emphasis? Should I seek a lot of mainstreaming or a little of it, and should I seek out its most challenging or least challenging forms?

\section{MORE ACADEMICS OR LESS?}

This quandary actually stems from an old question: Should a child with Down syndrome ever be in a class labeled "educable" (one that features academics) or only in 
a "trainable" class (one that features nonacademic subjects such as self-care)? Today, classes labeled either educable or trainable are much fewer than before, but the issue that originally separated one from the other-the presence or absence of an emphasis on academics-is still much in evidence. For instance, many educators doubt that a child with Down syndrome can really learn to read. To them, recognizing signs such as "men" is feasible, but they doubt that children with Down syndrome will ever be able to read with any proficiency. The doubters are in error. How do we know this? Because we have research findings to prove them wrong. 1

\section{Never Educable? Always Trainable?}

During the 1970 s portrayals of the educational potential of many groups of children with mental retardation were becoming increasingly optimistic. Educational expectations for children with Down syndrome, however, were not keeping pace. In 1975, the same year the Education for All Handicapped Children Act was passed, an article appeared in a popular magazine, Psychology Today, that cast serious doubt on the educability of children with Down syndrome. In that article the chief of the Reproductive Genetics Unit in an eastern university hospital was quoted as saying, "You show me just one mongoloid that has an educable IQ.... I've never seen even one [who is educable] in my experience with over 800 mongols."2 (In 1987, Psychology Today, on its own initiative, published an article offering an updated portrayal of the overall achievements of people with Down syndrome. ${ }^{3}$ )

Up to this point, we have been discussing educability from an academic perspective. But the chief of the Reproductive Genetics Unit who was just quoted is viewing it from an intelligence test viewpoint. From an intelligence test perspective, educability generally refers to an intelligence test score (an IQ) falling somewhere between 50 and 75. Because schools often rely heavily on an IQ score as a predictor of academic potential, IQ and academics will be discussed together in the sections that follow.

Responding to the 1975 Psychology Today article, we conducted an extensive computerized search of the literature on Down syndrome to determine whether the physician's assertion could be countered with experimental findings. A search through 10 years of research literature yielded nearly 650 references, of which 105 contained data pertinent to the question of educability. Although we were able to demonstrate that several persons with Down syndrome across the 105 studies exhibited educability from an IQ standpoint, ${ }^{4}$ our argument for raising educational expectations was far from being strong back in 1978 because long-term evidence of educability was unavailable and academic achievement outcomes that could demonstrate educability from a functional perspective were almost nonexistent at that time.
Now, fortunately, at least four early intervention studies have produced findings that bear on these concerns.

\section{IQ and Academic Ability in the Early Years of Schooling}

The first of these studies comes from Macquarie University in Australia. ${ }^{5}$ Results of this study showed that eight children who had been in an early intervention program with an emphasis on reading through the application of behavior modification techniques and integrated programming were, at around age 8, reading at a level that came close to their chronological age. Moreover, although the IQs of these children were not unusually high (which helps to mitigate the argument that they were reading well only because they were "hand-picked"), five of the eight children had IQs in the educable range.

The second study ${ }^{6}$ was directed at the academic abilities of young children with Down syndrome in Great Britain. Buckley and Wood had been teaching a group of fourteen preschool-age children with Down syndrome in a homebased, parent-as-teacher program. Their sample also seemed to be a fairly representative one because it included all of the children with Down syndrome between 2 and 4 years old living at home across two entire health districts. Their findings revealed that several of these young children were developing good beginning reading abilities. Furthermore, twelve of the fourteen had developmental quotients (early indicators of later intelligence quotients) in the educable range.

Nevertheless, parents who have a child with Down syndrome should be alerted to a problem that becomes a trap they sometimes create unwittingly for themselves and then step into. The trap-actually, a trapping misperceptionusually is approached through a sequence of two steps:

1. Because young children with Down syndrome who have been in an early education program frequently score in the educable IQ range at the end of that program, parents often stress the importance of IQ in making their educability argument at school entrance. Suppose they are successful in placing their child (who has an IQ in the educable range) in an educable class. So far, so good, but the trap is about to be sprung.

2. Parents, having argued successfully for an educable class placement based on an IQ in the educable range, continue to fight for a succession of educable class placements as their child grows older, continuing to base their advocacy efforts on annual intelligence testing results. They now have all of the "eggs in the IQ basket." The trap is about to catch them because the IQs of most children with Down syndrome diminish as they grow older, making their 
parents' argument for an educable placement more difficult each year if they rely heavily on intelligence test findings.

This does not mean that children with Down syndrome aren't learning more as they grow older, including lots of things that are more important than what is reflected in an IQ test resultsuch as how to set an alarm clock accurately, read labels on canned goods correctly, identify the bus that will drop off the child near home, getting on bus 33B rather than 33C.

To offset an overemphasis on IQ as a deciding factor in assigning a child with Down syndrome to a class emphasizing academics or one emphasizing self-help skills, parents should insist that abilities central to the substance of educability receive much more attention during the assessment and placement planning process. For example, during a placement conference, parents should talk about their child's interest in books. Relatedly, the child's conceptualization ability, language repertoire, and quality of instructional socialization should be assessed.

Parents will be on firm ground if they insist on a richer and more in-depth assessment of these practical indicators of educability if they look to the results of the Macquarie early education project. ${ }^{7}$ After the children in the Macquarie project had been integrated in regular schools, follow-up data were collected. When the children's IQ and reading achievement outcomes were compared, IQ and reading achievement were poorly correlated. Hence, if IQ is heavily emphasized, the risk to making a valid educational placement decision should be obvious.

Although these findings might help parents advocate effectively for a trial placement in an educable class for their son or daughter at the time of school entry, these findings are not sufficient to convince skeptical decision makers of children's chances of profiting from academic instruction in their later years.

\section{IQ and Academic Ability in the Middle Years of Schooling}

In one study8 DuVergeas examined the reading abilities of children with Down syndrome who had been in an early education program in Seattle, Washington, from the time they were 18 months of age. In the University of Washington program, systematic educational stimulation had been offered to fifty children with Down syndrome. Children came from all socioeconomic levels, were from natural as well as foster homes, and were enrolled early in the preschool period-some as newborns. The goal of the Washington program was to promote children's abilities across many curricular areas (cognitive, self-help, motor), with an emphasis on the use of behavior modification. The reading scores and IQs of these children when they were about 14 years old ranged widely, demonstrating grade equivalents that represent substantial academic achievement, although IQs of three of the six children fall currently in the trainable range (IQ below 50).

The second early education study that has investigated long-term academic achievement levels in children with Down syndrome is the EDGE project. ${ }^{9}$ We found that across the fifteen children in the experimental group in the Twin Cities, twelve of the children were in educable classes or in regular-educable class combinations at around age 13. (The relatively favorable proportion of educable-to-trainable placements undoubtedly relates to the fact that EDGE personnel helped parents in the Twin Cities area advocate for an educable class if that placement seemed warranted.)

Of central importance for the purpose of addressing the educability issue is that eleven of fifteen EDGE children were reading with comprehension at or above the secondgrade level as adolescents. To us, one of the "acid tests" for advancing the argument for educability is being able to show evidence of attaining a reasonable level of reading proficiency, particularly reading with comprehension, in children with Down syndrome.

Evidence of educability extracted from the studies reviewed here should not be construed as a rationale for fulltime placement of all children with Down syndrome in a class labeled "educable." This might easily happen because we have been advocating here for upgrading educational expectations. Some children with Down syndrome, however, prosper in a regular class on a part-time, or even a fulltime, basis. To buttress this point, we focus again on the development of eight children with Down syndrome who had gone through the Macquarie early education study and had been placed in regular classes with itinerant specialist support. The investigators in that study reported that children with Down syndrome functioned comparably to the nondisabled students in terms of social and reading abilities (both oral reading and reading comprehension). ${ }^{10}$

In a similar vein, as was pointed out earlier, several of the EDGE Project children were in educable-regular class combinations. By implication, however, a number of children with Down syndrome from the EDGE Project were in trainable classes. Although this should not mitigate our argument for raising educational expectations in general, we do not contend that a trainable placement is never appropriate. To the contrary, some children (but far fewer than once thought) may profit from a trainable class placement, at least part of the time, possibly because of severe cognitive limitations coupled with serious adaptive behavior impairments or absence of the types of support needed to sustain them properly in an educable class.

Based on the corrective influence of updated evidence found in the results of these four studies, parents presumably 
now should be in an excellent position to argue convincingly that children with Down syndrome are not always only trainable in terms of their educational functioning. Some profit from a continuous emphasis on academics throughout their schooling, blended in as a part of vocational preparation and community living in general. We do not favor "pushing" academics to the neglect of other school subjects, however, nor do we favor emphasizing formal academic instruction with a youngster who is incapable intellectually or functionally of handling it. We do contend, though, that most children with Down syndrome can become fluent enough in the three Rs to be termed "functionally literate"for example, able to read essential portions of the newspaper and other documents needed to live relatively independently, capable of handling money in conducting fundamental financial matters such as maintaining a savings account and paying fares on public transportation, and able to print or write notes using correct spelling.

Showing that children with Down syndrome are capable of attaining functional literacy offers little specific information about how functional literacy can actually be attained. We turn to this subject next.

\section{PROMOTING ACADEMICS}

Students with Down syndrome who have mild intellectual impairments (often referred to as "educable") do not learn to read simply because a teacher chooses the "one best" reading textbook and uses it systematically. First, there doesn't seem to be one best reading textbook series, and furthermore, there is no one best method of teaching reading either. ${ }^{11}$

According to Leeper, ${ }^{12}$ what is known is that students classified as educable:

- can and do benefit from traditional reading approaches.

- respond to incentive systems - for example, receiving tokens for learning to match words with their corresponding pictures.

- benefit from reading materials that have doublespaced lines of print and uneven righthand margins.

- benefit from a carefully worked out scope and sequence of instruction.*

Several curriculum materials are available for students who are beginning to develop a vocabulary of words based on recognizing their appearance (a "sight vocabulary") and those who are able to sound out some words and parts of words (decoding the sound of words and their parts, also known as "phonics"). For instance, the DISTAR reading program, Sullivan programmed readers, and the Edmark

\footnotetext{
* Mainord and Love ${ }^{13}$ and Anderson ${ }^{14}$ have delineated a helpful scope and sequence for the early stages of reading instruction, presented in the text from which this article comes (p.325).
}

program all have been shown to have good-to-excellent outcomes with students classified as educable. ${ }^{15}$

Another way to help decide which approaches might be effective is to ask experienced teachers of educable-level students what materials or methods they use the most. Their favorites include:

- an instructional approach combining phonic, sight word, and language experience elements.

- assessing student interests and characteristics to determine level and nature of reading instruction.

- teacher probing of students' understanding of content they have read.

- a special reading series or sequence of worksheets.

- small-group or individual techniques to promote reading. ${ }^{16}$

The first item conveys the message that teachers prefer a combined instructional approach, one involving phonics, sight words, and language experience. We've briefly described the phonic and sight word approach, but what is a language experience approach?

Language experience approaches capitalize on the fact that reading is essentially spoken language in printed or written form. Thus, words the child speaks vocally and understands can be used to compose simple sentences that he or she can read as well as speak. An adult or peer tutor can write down these words and give them to the child to read aloud, cementing the understanding of sound-symbol correspondence that is critical to reading. In addition, the child can begin to compose simple stories, possibly using a typewriter or word processor. Typing can be a boon for some students with Down syndrome who have difficulty using a pen or pencil skillfully.

Likewise, it is important for the child to hear words that someone reads at the same time the child sees them in printed form. As conveyed in Chapter 5, the benefits of reading to the child while the child is trying to decode the written words as he or she hears them and looks at pictures supporting the text cannot be emphasized enough. Not only is reading ability advanced in this way, but so is intellect, language, and socialization in the bargain.

Reading for understanding (not speed), comprehension (not just "word calling"), and acquiring not only a sight vocabulary but also learning how to decode words should be emphasized. Above all, it is important to keep in mind that the success of day-to-day living as an adult rests far more on social factors than academic factors. Yes, academic proficiency is nice, and is even linked to some extent to socialization-but the ability to get along with people and work successfully with them will be far more important in the long run.

Many (perhaps most) students who have Down syndrome will find arithmetic to be their most challenging subject. Particularly difficult will be the arithmetic problems called 
story problems ("If Jane has 8 apples and 3 oranges and gives one orange to...") because they involve remembering and manipulating numerals, words, and symbols in the mind and on paper while moving to a solution. Although children with Down syndrome usually become proficient in using basic arithmetic facts such as adding a column of numbers, many do not do nearly as well with story-type problems.

Because of these difficulties with arithmetic, parents often use "crutches" or alternative devices to help their child over trouble spots or try to help them avoid particularly tough areas altogether if they can. For instance, instead of learning to use a wristwatch with hands, a watch that gives a direct digital readout of the time does the same job just as well. An inexpensive, hand-held calculator can help the person decide how much money to put on the counter to pay for three postage stamps. Or this problem can be "crutched" by teaching the person to reliably identify a one-dollar bill and to feed it into the correct slot of a vending machine in the post office lobby to obtain three stamps, letting the machine make the change.

With respect to writing, students with Down syndrome might be expected to write about as well as they read because of the relation between reading (the meaning of print comes off the page) and writing (the understood print goes back on the page). In contrast to reading, however, writing requires sophisticated arm and finger movements, a fine-motor skill that is difficult for many students with Down syndrome. Because of fine-motor demands in writing legibly, teachers are making more use of the typewriter or word processor with children who can type more easily than they can print or write.

\section{SCHOOL MAINSTREAMING: WHAT KIND? HOW MUCH?}

Tom, a student with Down syndrome, and his parents share a dream for his life. The dream is that Tom will become an adult who will be able to live semi-independently in an apartment, hold a job, and participate in a variety of social and recreational activities in his community. If Tom is to succeed in living out this vision, he will need to be able to interact successfully with roommates, bus drivers, store clerks, employers, co-workers, and other people in the community. Thus, each opportunity he has to interact meaningfully with a nondisabled person in school represents valuable preparation for the transition from school life as a student to community life as an adult.

\section{What is Mainstreaming?}

Mainstreaming can be considered a general or a specific term, can be used as a noun or a verb, and can take many forms. Generally, it is used to describe integration or inclusion in a regular school, often in a regular class, for part or all of a student's instructional time. Mainstreaming tends to be an educational term, whereas integration or inclusion refers to broad movements within society in general, including schooling.

Sometimes parents and professionals join in advocating for a given philosophy or policy. A case in point is the push by some to mainstream all school-age children with Down syndrome in regular classes $100 \%$ of the time. No exceptions. (This movement is often referred to as "full inclusion.") One has to look beyond the rhetoric of a philosophical statement, however, to see how it squares with the needs of an individual child in a specific setting, matching the support elements in a learning environment to the child. In adopting this perspective, we may decide to enroll a youngster temporarily in a segregated summer camp rather than an integrated camp because the qualities of the integrated camp don't fit the child's needs at that time. In this regard, suppose that a child with Down syndrome tends to behave impulsively (runs away from a group abruptly). Suppose, too, that the integrated camp promotes an open activity arrangement; campers are expected to go from area to area on their own. The segregated camp, on the other hand, offers "follow the child" supervision. For the child's safety, if for no other reason, we would choose the segregated camp because it provides the type of support this child needs.

Obviously, an alternative would be to find an integrated camp that provides "follow-along supervision" so as to achieve inclusionary programming. Unless that crucial support element is provided, however, the integrated camp, even though it is in tune with prevailing educational and societal philosophy, is not a good bet for this child. If we push the child into an integrated experience without the supports needed, we risk upsetting his progress because his problem likely will be intensified by the situation, and he (and we) will have to live with its consequences.

A neighbor's daughter, Jean, has Down syndrome. The neighbor insisted on her daughter being in a regular class $100 \%$ of the time, even though her regular education classmates never had received any training in how to be a peer companion or to value cognitive diversity. They rejected Jean in dozens of small and large (but all hurtful) ways. Each afternoon when school ended, Jean came home alone, often in tears, withdrawing into the world of TV, eating her way into obesity. The situation worsened as she became heavier and received even more rejection because of it. The regular class teacher, though well-intentioned, was a firstyear teacher struggling to survive and had few skills in dealing with large differences in ability.

Jean's self-esteem sank lower and lower, finally reaching the point where she skipped school to wander about aimlessly in the nearby shopping center because school was too painful for her to face. She also developed illnesses (some from environmental causes, some probably psychosomatic), which enabled her to stay home in front of the TV. 
Encouraging the neighbor to place Jean temporarily in a resource room in the school, where the special education teacher had a flair for building self-esteem, fell on deaf ears. Jean's mother insisted that the regular class, and only the regular class, was appropriate, "even if she's miserable in it every moment" (the mother's words). Sadly, Jean's mother had elevated regular class placement to Holy Grail status, unrealistically so, of course, as most of us have experienced one or more inadequate regular classes.

Fortunately, before Jean developed full-blown depression or ran away from home, the school psychologist referred Jean's case to the school's child study team, which unanimously endorsed special education resource room placement for most of her school day. After several due process hearings, Jean's mother reluctantly agreed to the resource room placement.

After 2 years in the special education resource room, Jean was reintroduced gradually to a regular homeroom class (not the original one), where the teacher had skills in structuring activities for cooperative outcomes, had instructed Jean's regular education classmates in how to be successful peercompanions, and had made the valuing of diversity a central theme of classroom activities. Jean blossomed in that environment, graduating with her regular education classmates and receiving applause from them at the graduation ceremony - applause that was genuine and strong.

The point of this anecdote is obvious: The support elements of an environment, segregated or integrated, or a combination of both, must match the needs of the individual being considered for it. If an integrated environment has the proper support elements, or they can be provided with reasonable dispatch, it is probably a better choice than a segregated environment because of its relatively richer curriculum and the more advanced social and cognitive repertoire of nondisabled peers from which the student with Down syndrome can learn. If, however, a mainstreamed setting is a poor match for the child's needs, it can become a more restrictive environment rather than a less restrictive environment, regardless of its philosophical intent.

The environmental supports each child with Down syndrome needs are highly individualistic. Some questions to ask in considering an integrated program are brought up next.

\section{Considering an Integrated Program}

Does the Program aim for mutuality of benefit? If it is to prosper, integration should provide benefits to students with and without disabilities. Fortunately, our research over the last 12 years shows that achieving mutuality of benefit is not difficult if the techniques about to be described are employed properly. Not that the benefits of integration are identical to both groups. They are not. They are equally important though: People with Down syndrome improve their social abilities and activity skills; those without disabilities grow in their self-confidence and regard for people with disabilities and have a better grasp of their own selfworth. (In the old days, that was referred to as "character building"; today it is called "values-based education.")

Does the program try to include children with Down syndrome in the child's circle of friends? Well-intentioned, but we believe misguided, insistence that the only legitimate friend for a child with Down syndrome is a nondisabled child effectively excludes relationships with others who have Down syndrome or another type of disability. This in itself is a form of segregation.

Often, insisting on having only nondisabled children interact with a child who has Down syndrome is based on parents' assumption that if their child establishes friendly relationships with nondisabled children, these relationships will become genuine friendships and carry over to adulthood strong and intact. Lasting friendship, however, is based on two people having interests in common, and reciprocally sharing things that enhance the depth of the relationship. This match-up of interests and things to share reciprocally is hard to sustain between people who have highly different levels of ability.

Today, adults with Down syndrome can and do have many nondisabled acquaintances in the community, but few of these can be regarded as close friends as we know them. When we asked EDGE parents to name their young adult sons' or daughters' close friends (buddies, people they like to be with the most), the forty-five individuals named (three each for the fifteen EDGE participants) were, with few exceptions, people with disabilities - many with Down syndrome. Even though most EDGE participants attended regular schools and many attended one or more regular classes throughout their school years and participated in many integrated activities outside of school, their young adult friends are mainly people with disabilities. Actually, it would be surprising if it were otherwise, considering that our own friends are very much like ourselves. Why would we expect this to be different for people with Down syndrome?

Does this finding somehow weaken the social and educational policy that encourages parents to advocate for mainstream placement if they desire it? Emphatically not! It does say, though, that in our earnest attempts to help people with Down syndrome to relate effectively to nondisabled people, we not cut them off from relating to people with Down syndrome and other disabilities.

Does the program take advantage of choice-making opportunities? Integration into activities does not automatically guarantee enjoyment for people with Down syndrome. After working many months to achieve schooling integration, parents and teachers may be frustrated because some people with Down syndrome do not want to participate in these integrated activities. Failing to consider personal preferences 
will undermine even the most noble and enthusiastic integration efforts. Fortunately, individual preferences can be considered by allowing people with Down syndrome to sample various preselected activities and then to choose activities in which they wish to participate from those samples. Research has shown that, when people with disabilities are allowed to choose the activities in which they wish to take part, they are more eager to learn the skills necessary to participate and they generalize in those activities more readily. ${ }^{17}$

Does the program neglect safety in the name of integration? A boycott of classes happened at one elementary school when parents kept their nondisabled children at home because of fear for their safety. The concern was evoked by a mainstreamed child with disabilities who was abusive toward other children, being aggressive toward them without warning. Although the school's commitment to including this child in general education classes for the entire school day is admirable, jeopardizing the safety of other students is inappropriate. We should remind ourselves occasionally that our society, while valuing altruism, also has a vigorous litigious element. Emphasizing the safety of all participants as a first concern will reap benefits for everyone in the program. Then, judiciously, inclusion can be done in small doses, moving carefully to larger doses as the student with a disability and his or her peers adapt in a supportive atmosphere.

Does the program have nondisabled peers assume "adult" teaching roles? Occasionally a nondisabled peer is asked to assume a role that an adult should assume. Peers without disabilities should not teach "heavy-duty" skills. As examples, a nondisabled peer should not be expected to teach a peer with a disability how to apply deodorant, put on undergarments, or brush teeth. These tasks are best left to adults such as parents and teachers.

\section{Guidelines for Providing a Good Integrated Program}

The remarkable law, Public Law 94-142, the Education for All Handicapped Children Act of 1975, which mandated that all children, regardless of the type or severity of disability, have a right to a free, appropriate public education in the least restrictive environment, has created unprecedented opportunities for parents seeking to integrate children with Down syndrome into regular schools. To take advantage of these opportunities, we have developed a set of guidelines for parents and teachers.

Guideline 1: Structure activities to promote cooperative interactions. ${ }^{18}$ Without structuring a mainstream situation for cooperative interactions, nondisabled individuals often view their peers with disabilities in negative ways, feel discomfort and uncertainty in interacting with them, and sometimes even reject them overtly. Unless the setting is structured for cooperative learning experiences, negative competition is likely to emerge and actually socialize children without disabilities to reject peers who have Down syndrome. What does structuring an activity for cooperative interactions mean?

Usually, one of three models of activity structure is applied when instructing a group of people: competitive, individualistic, or cooperative. Each is legitimate and has strengths in specific situations. Furthermore, these can be combined in an activity at times. We shall define each of them and look briefly at some of their applications.

Competition in its traditional application leads to one person in a group winning and all other group members losing. If it is applied to a group in which one or more of the members have disabilities that make success in a particular task difficult, the participants with disabilities likely will come in last in that task. As an example of competitive structuring in camping, imagine five children, some of whom have movement disabilities, lining up at the edge of a lake for a canoe race. Each has a canoe and a paddle to use. The camp director tells them that the person who reaches the other side of the lake first will win a miniature canoe paddle. Children with Down syndrome, who often (though not always) have coordination problems and poor muscle tone, have little chance of winning. Informed program leaders would not use a competitive goal structure in this manner, of course, but would modify the competitive situation or would rely on one or both of the following structures instead.

In an individualistically structured situation, each member of a group works to improve his or her own past performance. Potentially, every member of the group, including members with Down syndrome, can win a prize for improvement if the targets for improved performance are not set too high or are not matched inappropriately with a disability condition. Using the canoe example again, suppose the adult leader lines up the group on the lakeshore and says that last week when they paddled across the lake, each person's crossing time was recorded. Then the adult says that every person who improves his or her time will win a miniature canoe paddle, even if the improvement is slight. Now everyone can be a winner. This structure often is used in amateur athletics.

A cooperative learning structure, if handled properly, creates a natural interdependence because the group's attainment of an objective, with everyone contributing, is the quality that determines winning. Using the canoe illustration, the adult leader might have the five children climb into a war canoe (a large canoe), give each person a paddle, and tell them they are each to paddle as well as they can and they all will win a miniature canoe paddle if they work together to keep the canoe inside some floating markers (placed in such a way that perfection in paddling isn't required). The adult leader will need to paddle alongside to determine that everyone is paddling and to encourage them to support and assist one another.

To promote positive social interactions between participants with and without disabilities, the cooperative structure 
works better than the other two. In a competitive situation, each child is concentrating on paddling the fastest; he or she doesn't have an incentive for interacting socially. Similarly, in an individualistic structure each child is concentrating on bettering his or her own past performance; again, there is no incentive for interacting socially. In the cooperative structure, however, each person wants to encourage and assist every person in the group to achieve a group goal. This promotes positive interactions such as encouragement, cheering, pats on the back, and informal assistance.

Guideline 2: Clarify the purpose of a mainstreaming activity. If the goal is primarily social, structure it for cooperative peer socialization. If the goal is primarily task skill development, structure it for cooperative peer tutoring. Most programs promote both task skill development and socialization, but one objective may be given priority over the other at times. For instance, a 4-H club leader may designate certain periods of the year for project completion, such as the 2 months preceding the county fair. During these times nondisabled participants will be intent on finishing their individual projects. Socializing will be minimal, and nondisabled 4-H members intent on making "the best bookshelf ever entered at the county fair" may even regard it as a distraction.

The leader must be clear about the intent of the activity to avoid creating a situation in which participants are frustrated by trying to fulfill conflicting objectives. When skill development is the focus, the program must be organized so participants with and without disabilities are able to pursue that objective. When socialization is the focus, the program should be organized to facilitate that, and to do it in a way that will create mutuality of enjoyment. When both skill and socialization are to be emphasized, the organization will be different from either skill or socialization alone.

Guideline 3: Organize the program to suit the focus. The usual focus of a cooperative peer tutor program is to have a peer without a disability teach a skill to a peer with a disability. In a typical example of a cooperative peer tutor program, a 12-year-old child without disabilities works one-toone on teaching picture sequencing skills to a 6-year-old child with Down syndrome.

The focus of a cooperative peer socialization program is to promote positive social interactions between a child with a disability and a child without a disability. A typical application of this arrangement is one in which two young peers of the same age, one with a disability and one without, make a giant puzzle, then paint the pieces together, glue macaroni and yarn on the pieces together, and so on.

In structuring an activity for cooperative peer socialization, the following factors should be considered:

1. Age of peers. Nondisabled peers and peers with Down syndrome should be approximately the same age to create an expectation of friendly socialization, turn-taking, sharing, and so forth. If nondisabled peers are a year or two older, that's fine, but to encourage ongoing relationships, nondisabled peers in general should not be younger than their peers with Down syndrome. Our research shows that when children with disabilities are older than their nondisabled partners, the social interaction often is awkward. Same-age peer interactions can be thought of as "horizontal"-relatively equal and reciprocal.

2. Activity. Choose activities that are not overly skilloriented but, rather, are socialization-oriented. Structure task directions to reward mutual effort, not individual effort. An example is having a peer with Down syndrome and a peer without disabilities put ingredients on a pizza together and share in eating it later.

3. Preparing of nondisabled peers for socialization.

- Show them how to prompt cooperative interaction ("Chris, let's paint this picture together").

- Show them how to encourage their partner's cooperative participation ("Bill, I'll bet you're good at sanding. Can you help me sand this tray?").

- Show them how to reinforce their partner for trying ("I like the way we painted the fence together. You're a good painter!").

4. Adult leader's role during peer socialization interactions.

- Encourage cooperative activity ("Mary, I'd like to see you and Joan take turns kicking the soccer ball").

- Reinforce cooperative interactions ("I like the way you're setting the table together").

- Redirect participants back to the cooperative task when one or both become distracted.

- Step in if a socialization problem arises between participants.

5. Limitations. The purpose of cooperative socialization is to promote positive social interactions. It will not further skill development in a specific task in a child with Down syndrome (unless, of course, the targeted skill is social interaction itself). If the teacher's goal is to assist a child with Down syndrome to become a proficient reader, an older nondisabled peer (peer tutor) or an adult will probably have to provide reading instruction and guided reading practice. Cooperative socialization would not meet this task skill development goal very well.

Structuring a situation for cooperative peer tutoring requires consideration of the following factors:

1. Age of peers. Nondisabled companions should be considerably older than the partner with Down syndrome 
(twice as old is a good rule of thumb), as the main purpose of tutoring is to enhance the tutoring recipient's skill in some task. We refer to this relationship as vertical ("I'm the teacher; you're the student"). And, because it's a vertical relationship, the real teacher has to watch over it so the older nondisabled student doesn't become dictatorial or over-mothering.

2. Activity. Activities should feature cooperative skill teaching and practice in the skill instead of socialization. An example is found in the older nondisabled student teaching the younger child with Down syndrome to use a hand mixer. After giving the younger child a chance to show what steps he or she can do correctly in using a mixer, the peer tutor teaches the younger child the steps he or she cannot do.

For instance, if the child with Down syndrome doesn't know how to identify the various speeds on the mixer's control dial, the tutor might label each setting verbally while pointing to the corresponding printed words on the dial. The tutor can show how the printed word on the dial translates into mixer speed as the dial is moved from speed to speed. After that, the tutor might print the words on pieces of cardboard and use them like flashcards until the child with Down syndrome can identify them quickly and accurately. After that is accomplished, the tutor directs practice in locating the dial position ("Turn to high"), watching for errors and hesitations. Finally, the speed dial operation is reinserted into the whole task of using a mixer to mix batter for a cake. Food becomes the reward for achieving this cooperative outcome, and both enjoy a piece of cake together for their joint effort, a cooperative outcome.

3. Preparing nondisabled peers for tutoring.

- Show them how to use a variety of instructional techniques such as modeling, reinforcing, prompting, and fading.

- Show them how to adapt tasks to make them more accessible for a child with Down syndrome.

4. Adult leader's role during interactions.

- Reward the nondisabled child's tutorial attempts, and reward attempts by the child with Down syndrome to respond to the tutoring.

- Model good instructional techniques for the two children.

- Step in to prevent or correct instructional problems.

- Redirect participants if off-task behavior occurs.

5. Limitations.

- The social dynamics in a tutoring situation can turn autocratic or over-mothering if not watched carefully.

- The tutor may lose interest in instruction if the partner's progress is slow. The teacher can blunt this possibility by keeping the cooperative structure in place, tying rewards to something under the tutor's control, such as number of practice trials given, rather than to the recipient's success (though success usually results when the task, or step of the task, is broken down into small, simplified segments). The outcome of the task can be rewarding itself, as in the case of the batter-mixing task, in which the finished cake becomes a reward for both peers.

A third type of structure-one that should become increasingly popular-is the cooperative tutoring/cooperative socialization combination in which, for example, an older nondisabled peer tutors a younger peer with Down syndrome and at the same time a nondisabled peer of the same age as the child with Down syndrome serves as a socializing partner. This structure has some advantages. First, because of the participants' age differences, the older nondisabled peer can assume either a teaching or a socializing role, one that feels comfortable to him or her. Second, if teaching becomes necessary to achieve a task, the older nondisabled peer is available to do it and the younger nondisabled peer can concentrate on socializing. Third, this structure, with its varying participant ages instead of a single age (a structure we've dubbed the "one-room school" model), takes advantage of age and ability differences that are familiar because they occur naturally in families. As an example, a young nondisabled child and a young child with Down syndrome, both of whom are nearly the same age, ride horses together at the local stable (cooperative socialization). At the same time, an older nondisabled peer teaches riding skills to both of the younger children (cooperative tutoring).

Guideline 4: Recruit nondisabled participants in an appealing way. A helpful tool for recruiting nondisabled participants, as well as adult volunteers, is a slide presentation showing people with and without disabilities interacting in natural and interesting ways.* This produces a positive image for prospective participants, many of whom may have negative mental pictures of mainstreaming programs because they lack exposure to people with disabilities, or even have a negative stereotype of those with disabilities. Recruitment presentations that depict positive interactions between individuals with and without disabilities help create the expectation by potential members that they will have a positive experience

\footnotetext{
* If you photograph your own slides, obtain written photo-use permission for each person in your pictures (for minors or others unable to legally sign for themselves, have the parent/guardian sign). Also, inform all parents or guardians of your intent to provide an integrated program and receive consent to have their son or daughter participate. Although this type of permission may not be required, it is important to avoid misunderstanding. By the way, a videotape can serve this purpose and has some advantages to slides. However, playback requires more planning.
} 
in an integrated program. That expectation alone can go a long way toward creating a successful program.

Guideline 5: Strengthen nondisabled participants' understanding of disability. Meetings involving nondisabled group members and adult leaders should take place frequently, perhaps immediately before or after a mainstream session. During these meetings the discussion can cover a problem in interaction and how to overcome it, new ideas for interacting, task adaptation, and specific techniques that can be used during one-to-one activities. Knowledge of disabilities and their consequences can be broadened and strengthened in these meetings through the Special Friends curriculum. ${ }^{19}$

The following topics often are discussed with nondisabled participants in short, informal group discussions of 15-30 minutes between interaction sessions. Suggested topics include:

- How do we play together? Discuss how companions take turns, say nice things to each other, help each other when a task is difficult, stay close to each other when playing, smile at each other, and so forth. Reinforce the interaction techniques they have been taught to apply during integrated activities.

- How do we communicate? Discuss communication tips, such as talking slowly, allowing time for a response, trying another way to communicate if a companion doesn't understand, and not giving up. Common, simple manual signs ("hello," "good," "you," "me") can be introduced, too, if applicable.

- What is a prosthesis? Discuss the use of tools (ladder, paintbrush, and the like) that people without disabilities need so they can do certain tasks (such as paint a house). Show examples of a prosthesis (for example, an artificial limb or adapted equipment), and explain how it is like a tool that people without disabilities use.

- How does a person with a disability live in the community? Invite a person with disabilities to come and talk about how he or she travels from home to work, goes camping, and performs similar activities.

- What is a best friend? Discuss the nature of friendship. Ask participants to think about similarities and differences in their relationship with their friend with a disability and their best friend (if they are not the same person).

Guideline 6: Develop a cooperative social support network. The first five guidelines mainly provide information about how to promote cooperative interactions directly-for example, how the teacher rewards cooperative tutorial or socialization interactions. A teacher can use other methods, too, growing out of a group counseling tradition, methods that promote cooperative interactions less directly because the people involved bring their minds together for a common purpose. Two of these techniques, which have the cooperative planning approach in common but from a slightly differing perspective, are Circle of Friends ${ }^{20}$ and the McGill Action Planning (MAP) system..$^{21}$ These two often are used together or sequentially.

The Circle of Friends activity often begins using a targetlike piece of paper, which the teacher asks the parents or other key informant to fill out on behalf of the student who has Down syndrome (the student with Down syndrome may be capable of filling out a Circle of Friends sheet, too). In the innermost circle, the parent writes the names of individuals who are extremely close friends of the student, indispensable individuals other than relatives. In the circle next to the center one, the parent writes down names of all the people who are good friends but not indispensable friends. Circles three and four further expand the names of people outward until the list of people involved in the student's life in some manner is exhausted. In this way the teacher and parent are able to determine the number of people who are close to and interact with the person with Down syndrome. These people will become part of the MAP system, along with relatives and staff members who together will become a social support network, an actual circle of friends for the individual who has Down syndrome.

In the MAP system the teacher assembles people who are important in the child's environment, especially those in the inner one or two circles of the Circle of Friends. Often a parent becomes the most important member of the planning group, although the teacher usually acts as facilitator. Sitting around a table, the child's parent, siblings, one or two classmates, a teacher or two, perhaps a scout leader or other community-based person who is important in the child's life, and other people, including the child who has Down syndrome, "think out loud" about the following points, keeping in mind that successful integration in the community is the primary goal:

1. What is the individual's history?

2. What is your dream for him or her?

3. What is your nightmare?

4. Who is the individual?

5. What are his or her strengths and weaknesses?

6 . What are the individual's needs?

7. What would his or her ideal day look like, and what must be done to achieve the ideal?

These questions are written on large sheets of paper and become a "map" to the individual's future. From the notes generated through this method, short-term and long-term goals are written, followed by a list of steps or tasks that will have to be accomplished to attain the goals. Let's take a look at an example of these two techniques (Circle of Friends, MAP) in action. 
Megg is a 10-year-old child with Down syndrome who attends a regular school, where she is mainstreamed into several curricular areas and has a regular class as a homeroom base. Megg is easy to have around-unfortunately, too easy to have around sometimes, because she is very withdrawn socially. Her pencil-drawn Circle of Friends shows no child, older or younger or of the same age, who can be considered as an indispensable ("best") friend. Her mother does show two girls" names in the second circle (the "good friends" circle), though, girls who are in Megg's 4-H club and have shared pizza with her a few times at club meetings.

Working closely with Megg's mother, individuals important to her life, including the two 4-H companions, are brought together to develop a MAP for her. One of the first things brought out is that Megg's mother's nightmare is that Megg will be totally without friends as an adult and that she will be placed in a highly segregated and isolated residential facility when her mother dies, spending her days lonely and depressed.

On the brighter side, Megg's 4-H leader says that Megg has a nice smile (when she displays it, which isn't too often) and good manners. The participants decide to build on these, creating opportunities in which social interaction demands will be moved up a notch but will not be overwhelming for Megg. Her 4-H leader decides that Megg will have a nonspeaking role in the next Share the Fun skit-not a big role but one that perhaps will draw her out a little bit.

Megg's mother and teacher decide that Megg also will be encouraged to train for the Special Olympics volleyball event, joining teammates with and without disabilities through a Unified Sports program that meets at her school twice each week. Megg enjoys volleyball very much and does reasonably well in it. The volleyball coach becomes part of the MAP system, learning more about how to structure cooperative activities for athletes with and without disabilities so they succeed collectively as well as individually. Some of these activities take form in cooperative peer tutoring (nondisabled teammates showing how to serve, pass the ball, rotate, and so forth). Other activities take form in cooperative peer socialization (nondisabled peers encourage Megg during the game, reward her with a word of praise for a good try, and interact with her socially during snack time after a game).

As a result of combining the Circle of Friends, MAP system, and cooperative learning techniques, Megg is beginning to grow in her socialization abilities and volleyball skills. Her day-to-day life shows new vitality, too-new friends, both with and without disabilities; more variety in her socialization sphere; a schedule that gets her out of the house regularly and into worthwhile activities.

\section{NOTES}

1. J. Rynders and J. Horrobin, "Always Trainable? Never Educable? Updating Educational Expectations Concerning Children with Down Syndrome," American Journal on Mental Retardation 95 (1990): 77-83.

2. R. Restak, "Genetic Counseling for Defective Parents: The Danger of Knowing Too Much," Psychology Today 9 (1975): 92, pp. 42-46.

3. C. Turkington, "Special Talents," Psychology Today 21 (1987).

4. J. Rynders, D. Spiker, and J. Horrobin, "Underestimating the Educability of Down's Syndrome Children: Examination of Methodological Problems in Recent Literature," American Journal of Mental Deficiency 82 (1978): 440-448.

5. M. Pieterse and Y. Center, "The Integration of Eight Down's Syndrome Children into Regular Schools," Australia and New Zealand Journal of Developmental Disabilities 10 (1984): 10, 11, 20; and D. Lane and B. Stratford, Current Approaches to Down's Syndrome (East Sussex, Great Britain: Holt, Rinehart, \& Winston, 1987).

6. S. Buckley, "Attaining Basic Educational Skills: Reading, Writing, and Numbers," Current Approaches to Down's Syndrome, edited by D. Lane and B. Stratford (East Sussex, Great Britain: Holt, Rinehart, \& Winston, 1987), pp. 315-343.

7. Cited in Pieterse and Center.

8. A Comparative Follow-up Study of Down's Syndrome Children Who Attended the Model Preschool Program (unpublished doctoral dissertation, University of Washington, Seattle, 1984), cited in V. Dmitriev, "Cognition and the Acceleration and Maintenance of Developmental Gains Among Children with Down Syndrome: Longitudinal Data," Down's Syndrome, Papers and Abstracts for Professionals, Jan. 6-11, 1988.

9. Rynders and Horrobin.

10. In Pieterse and Center.

11. J. J. Carney, What Research Says About Reading for the Mentally Retarded Child (paper presented at the Annual Meeting of the International Reading Association, 1979).

12. T. Leeper, Teaching Educable Mentally Handicapped Students to Read: A Review of Research Literature (special report, Anoka-Hennepin Schools, Minnesota).

13. J. C. Mainord and H. D. Love, Teaching Educable Mentally Retarded Children: Methods and Materials (Springfield, IL: Charles C Thomas, 1973).

14. Paul S. Anderson, Language Skills in Elementary Education (New York: Macmillan, 1974).

15. This is according to Leeper's review.

16. P. Johnson, A Study of Selected Aspects of Reading Instruction for the Educable Mentally Retarded: Teacher Opinion, Instructional Procedures, and Materials (Tampa: University of South Florida, 1976).

17. D. Fletcher, Ensuring Enjoyment in Integrated Community Recreation and Leisure Activities (paper delivered at National Conference of American Association on Mental Retardation, May 1992, Atlanta, GA).

18. D. Johnson and R. Johnson, Learning Together and Alone (Boston: Allyn and Bacon, 1994).

19. L. Voeltz, H. J. Hemphill, S. Brown, G. Kishi, R. Klein, R. Fruehling, J. Collie, G. Levy, and C. Kube, The Special Friends Program: A Trainer's Manual for Integrated School Settings (revised) (Honolulu: University of Hawaii Department of Special Education, 1983).

20. S. K. Sherwood, "A Circle of Friends in a 1st Grade Classroom," Educational Leadership 48(3) (1990): 41.

21. T. Vandercook, J. York, and M. Forest, "The McGill Action Planning System (MAPS): A Strategy for Building the Vision," Journal of the Association for Persons with Severe Handicaps 14(3) (1989): 205-215. 